\title{
Line-orientation generalization in children and adults as a function of the number of training trials
}

JEFFREY S. LANDAU, Adelphi University. Garden City. L. I., N. Y. 11530

Children and adults learned to discriminate beti'e'n a vertical line $(S+)$ and its absence $(S-)$. Children reciled either 10 or 40 training trials while adults received either 1. 10. 20. or 40 training trials. All groups were then tested for line orientation generalization. The results showed that orertraining did not differentially affect generalization patterns. Children responded to all test stimuli while individual adults responded either to the vertical, the vertical and horizontal, or all test stimuli. The role of actiration and selection mechanisms in generalization performance was discussed.

Recently, mediational concepts have been employed to explain the results of stimulus generalization experiments (Doll \& Thomas. 1967: Landau, 1968: Tempone. 1966). The problem to be considered here is that of identifying parameters which may be related to the activation of concepts assumed to control line-orientation generalization behavior.

In the experiment reported by Landau (1968), children and adults were provided with discrimination training (i.e.. 90-W) in which $\mathrm{S}+$ was a black vertical line $(90 \mathrm{deg})$ on a white background and $S-$ was the white (W) background. Ss were then tested for line-orientation generalization with either one of two test orders (01 and 02$)$. The results showed that (1) both 01 and 02 children responded maximally to all test stimuli; (2) some 01 adults, as the children. generated flat generalization patterns while others responded to $S+$ only: (3) 02 adults responded to $S+$ only or responded maximally to the vertical and horizontal stimuli. Statistically, an Order by Test Stimulus interaction was obtained when the adult 01 and 02 group gradients were compared.

In training conditions in which $S+$ was a vertical line 190 deg) and $S-$ was an oblique line (120 deg or 150 deg). test order did not differentially affect test performance. Individual adult response patterns were comparable to those of the 90-W-02 adults. Children responded to the S+ test stimulus only.

It was concluded that a general concept (e.g.. "a line") mediated flat generalization patterns while specific concepts (e.g., "vertical." "straight") associated with training and test order parameters mediated S+ only and vertical-horizontal test patterns.

The specific problem addressed in the present experiment is the relation between number of training trials and generalization in the 90-W (single stimulus) training situation. It was assumed that increased observation of a single stimulus would increase the probability of activating specific concepts and thus increase the probability of altering the generalization patterns in a way comparable to that obtained in the vertical-oblique training condition. The predictions for adults were that (1) with few training trials, the Order by Test Stimulus interaction would be replicated: and (2) with increased training trials. vertical-horizontal and $S+$ only patterns would be obtained for both test orders. The prediction for nursery school children was that with increased trials the number of individual flat patterns would decrease while the number of individual $\mathrm{S}+$ only patterns would increase.

Subjects

METHOD

Thirty children in attendance at nursery schools in Queens.
New York, 1 ranging in age from $3^{1} z^{-4}{ }^{\prime} 2$ years and 80 introductory psychology students at Adelphi University. Garden City, New York. served as Ss.

Apparatus and Procedure

The stimuli (lines of variable orientation) were constructed by placing black tape strips on white cards. They were presented in a display box with two circular windows in horizontal alignment.

In Phase 1 . both children and adults werc given simultaneous $(90-W)$ discrimination training. S responded by saying "yes" and pointing to the "picture" ( $S+$ or $S-$ ) if hi" thought it was "rec" and hy say ing "no" if he thought it was not. The $E$ informed $S$ after each response as to whether he was correct or incorrect.

Groups of 20 adults were given either 1. 10. 20. or 40 trials while two groups of 15 children each were given either 10 or 40 training trials.

In the generalization phase all Ss were told that they would be shown a "few more pictures." that they "should continue as before" and that they would no longer be told if they were riglht or wrong.

There were six generalization test stimuli $130 \mathrm{deg}$. 60 deg. 90 deg. $120 \mathrm{deg}, 150 \mathrm{deg}$, and $180 \mathrm{deg}-$ horizontal). They were presented sllcessively for 12 trials (miximum of two responses per stimulus) and simultancously (c.g.. $30 \mathrm{deg}-(\mathrm{n} 0$ deg. 60 deg-90 deg) for six trials. Successice and simultaneous presentations were intermised over the test block. In the simultaneous condition. S wats permitted the option of selecting either or both stimuli. Thus. within the test block of 18 trials. S was provided four opportunities to respond to each of the six test stimuli.

Half of the adults in each training group received a different test sequence. In Order $1(01)$ oblique stimuli appeared initially. while in Order $2(02)$ horizontal stimuli appeared initially. Children received the 02 sequence only.

The apparatus and procedure described here were the same as that reported in greater detail in Landau (1968). One difference between the experiments. however. was that in the present case a simultaneous training procedure was utilized while Landau employed botl a simultaneous and successive within-Ss training procedure.

\section{RESULTS}

A four-factor mixed analysis of variance (Winer. 1902) was performed on the adult generalization data. The between group factors were training trials $(1,10.20$. and 40 trials $)$ and order (01 vs 02$)$ : the repeated factors were test stimuli $(30.60,90$. 120, 150. and $180 \mathrm{deg}$ ) and type of trial (simultaneous vs successive). The main effects of Order $[F(1.72)=9.01$, $p<.01]$ and Stimuli $[F(5.360)=23.94, p<.01]$, and the interaction between Order and Stimuli $[F(5.360)=0.26$. $p<.01\}$ were statistically significant. No other main effect or interaction approached significance.

Table 1 shows mean number of responses to test stimuli for adults and children in each of the training and order conditions. The Order by Stimulus interaction may be noted by inspection of the means which summarize test patterns across training conditions: 02 adults responded primarily to the vertical and horizontal stimuli while 01 adults generated relatively flat test patterns. Inspection of the test patterns for children indicated no difference as a function of training conditions.

DISCUSSION
The results of the present experiment did not support the 
Table 1

Mean Number of Responses to Test Stimuli for Adults and Children in Each of the Training and Order Conditions

\begin{tabular}{|c|c|c|c|c|c|c|c|c|c|c|c|c|}
\hline \multirow[b]{3}{*}{ Trials } & \multicolumn{12}{|c|}{ Generalization Test Stimuli } \\
\hline & \multicolumn{6}{|c|}{ Order 1} & \multicolumn{6}{|c|}{ Order 2} \\
\hline & 30 & 60 & 90 & 120 & 150 & 180 & 30 & 60 & 90 & 120 & 150 & 180 \\
\hline & \multicolumn{6}{|c|}{ Adults } & \multicolumn{6}{|c|}{ Adults } \\
\hline 1 & 2.40 & 2.20 & 3.70 & 1.80 & 2.10 & 2.70 & 2.00 & 1.50 & 4.00 & 1.80 & 1.90 & 2.00 \\
\hline 10 & 2.90 & 3.50 & 3.10 & 3.20 & 2.60 & 2.30 & 1.40 & 2.00 & 3.20 & 1.40 & 1.40 & 2.40 \\
\hline 20 & 2.80 & 3.20 & 3.60 & 3.20 & 2.80 & 2.80 & .80 & .80 & 3.90 & .80 & .80 & 1.00 \\
\hline 40 & 2.00 & 2.00 & 3.30 & 1.90 & 1.90 & 1.30 & .80 & .80 & 4.00 & .80 & .80 & 2.20 \\
\hline \multirow[t]{2}{*}{ Mean } & 2.53 & 2.73 & 3.43 & 2.53 & 2.35 & 2.28 & 1.25 & 1.28 & 3.78 & 1.20 & 1.23 & 1.90 \\
\hline & & & & & & & \multicolumn{6}{|c|}{ Children } \\
\hline 10 & & & & & & & 3.67 & 3.67 & 4.00 & 3.67 & 3.73 & 3.87 \\
\hline 40 & & & & & & & 3.46 & 3.20 & 4.00 & 3.20 & 3.34 & 3.40 \\
\hline Mean & & & & & & & 3.57 & 3.44 & 4.00 & 3.44 & 3.54 & 3.64 \\
\hline
\end{tabular}

hypothesis that overtraining would be systematically related to changes in line-orientation generalization behavior. Two explanations are suggested, both of which distinguish between parameters related to the activation of concepts and parameters determining the association of concepts to overt behavior.

The first explanation assumes (1) that $\mathrm{S}+$ activates several concepts in hierarchical order, e.g., "a line," "a straight line," etc., (2) that the concept highest in the hierarchy controls overt behavior, and (3) that overtraining strengthens all activated concepts but does not re-order the hierarchy. Thus, overtraining would not be expected to change overt behavior.

The second related explanation would posit that test procedures provide "information" which either (1) re-orders the hierarchy and thus produces changes in behavior and/or (2) determines the selection of a concept irrespective of its locus in a hierarchy. Thus, in the present experiment, overtraining may have increasingly activated specific concepts; however, "information" necessary for effecting re-ordering or selection processes may have been absent.

\section{REFERENCES}

DOLL, T. J., \& THOMAS, D. R. Effects of discrimination training on stimulus generalization for human subjects. Journal of Experimental Psychology, 1967, 75, 508-512.

LANDAU, J. S. Postdiscrimination generalization in human subjects of two different ages. Journal of Experimental Psychology, 1968, 76, 656-663.

TEMPONE, v. J. Mediational processes in primary stimulus generalization. Child Development, 1966, 37, 687-696.

WINER, B. J. Statistical principles in experimental design. New York: McGraw-Hill, 1962.

$$
\text { NOTE }
$$

1. I would like to thank Mrs. Jacobs, Director of the Corner School Nursery and Kindergarten, for her kind cooperation in providing Ss. 